\title{
Correction to: Use of diaphragm thickening fraction combined with rapid shallow breathing index for predicting success of weaning from mechanical ventilator in medical patients
}

Pattarin Pirompanich ${ }^{*}$ and Sasithon Romsaiyut

\section{Correction}

The original article [1] contained an error. The caption of Fig. 4 should be changed. The correct caption can be found below.

"Fig. 4 Receiver operating characteristic curve for right DTF: AUC 0.951 (95\% CI 0.88-1.00; p < 0.001), left DTF: AUC 0.700 (95\% CI 0.52-0.88; $\mathrm{p}=0.079$ ), and RSBI: AUC 0.709 (95\% CI 0.50-0.92; p = 0.067)".

Received: 27 March 2018 Accepted: 27 March 2018

Published online: 23 April 2018

\section{Reference}

1. Pirompanich $P$, et al. Use of diaphragm thickening fraction combined with

rapid shallow breathing index for predicting success of weaning from mechanical ventilator in medical patients. J Intensive Care. 2018;6:6.

https://doi.org/10.1186/s40560-018-0277-9.

\footnotetext{
* Correspondence: pirompanichp@gmail.com; pattarin@tu.ac.th
} Division of Pulmonary and Critical Care Medicine, Department of Medicine, Faculty of Medicine, Thammasat University, Pathumthani, Thailand Full list of author information is available at the end of the article 